\title{
Zero-a-seis
}

Revista Eletrônica editada pelo Núcleo de Estudos e Pesquisas de Educação na Pequena Infância

Artigos

Rafaela da Silva Melo

Rosangela de Fátima Rodrigues Soares ${ }^{2}$

\section{Infâncias Glitz: um estudo sobre as imposições dos concursos de beleza aos corpos infantis}

Resumo: A partir dos trechos extraídos de episódios do reality show Pequenas Misses (Toddlers and Tiaras) e das contribuições dos estudos da infância e da perspectiva teórica pós-estruturalista, busco analisar os discursos de "verdade" que sustentam a necessidade da transformação radical dos corpos infantis para atender às exigências dos concursos beleza. Discursos que tem servido de justificativa para as formas contemporâneas de exploração, abuso, disciplinamento e governo dos corpos infantis.

Palavras-Chave: Infâncias. Corpo. Modos de Subjetivação.

\section{Glitz childhood: a study on the charges of beauty contests to children's bodies}

Abstract: From the excerpts of episodes of the reality show Toddlers and Tiaras and the contributions of childhood studies and post-structuralist theoretical perspective, I try to analyze the discourses of "truth" that support the need for radical transformation of children's bodies to meet the requirements of beauty contests. Discourses that have served as justification for contemporary forms of exploitation, abuse, discipline and government of infant bodies.

Keywords: Childhoods. Body. Ways of Subjectivation.

\footnotetext{
I Aluna do Curso de Licenciatura em Pedagogia na Universidade Federal do Rio Grande do Sul. Classificadora Titular Externa do Projeto Classifique (Ministério da Justiça) atuando no apoio ao monitoramento de Jogos Eletrônicos e Aplicativos para Dispositivos Móveis. Bolsista de Desenvolvimento Institucional pela Fundação de Apoio à Universidade Federal do Rio Grande do Sul do Centro de Formação Continuada de Professores FORPROF/RENAFOR/UF.

2 Doutora em Educação e professora adjunta da Faculdade de Educação da Universidade Federal do Rio Grande do Sul. Membro do Grupo de Estudos de Educação e Relações de Gênero (GEERGE-UFRGS).
} 
Introdução

$\mathrm{S}$

orrisos ensaiados, figurinos com muito brilho, unhas e cílios postiços, bronzeamento artificial, ensaio: esta tem sido a rotina de muitas crianças que participam dos concursos beleza pelo mundo. Muitas destas "pequenas estrelas" como veremos neste estudo, ingressam neste "universo" desde os primeiros meses de vida.

Acompanhando a rotina das participantes dos concursos de beleza infantis no reality show "Pequenas Misses", exibido atualmente no canal de TV por assinatura Discovery Home \& Health é possível perceber que em cada episódio, determinados discursos se colocam como verdades incontestáveis: a de que os corpos infantis precisam ser radicalmente transformados para atender às exigências dos concursos.

Neste artigo, pretendo mostrar como as imposições dos concursos de beleza aos corpos infantis se apoiam em determinados saberes, sendo estes sustentados por uma rede de especialistas que os legitimam, com o poder de dizer a "verdade" que tem servido de justificativa para as formas contemporâneas de exploração, abuso, controle, disciplinamento e governo dos corpos infantis.

As Infâncias Glitz

Nas últimas décadas os estudos sobre as infâncias, crianças e culturas da infância vêm ganhando visibilidade, especialmente no campo da educação, da filosofia, sociologia, antropologia e do direito, porém focados em divergentes abordagens, enfoques e métodos, os quais determinaram distintas imagens sociais sobre as crianças. Os estudos culturais e da pós-modernidade apresentam a infância como uma categoria construída social e historicamente, sendo sempre contextualizada em relação ao tempo, ao local e à cultura, variando segundo a classe social, o gênero e outras condições socioeconômicas. Sendo assim, não há uma infância natural, única e nem universal para todas as crianças, mas múltiplas infâncias e crianças (DORNELLES, 2005; CORAZZA, 2000).

Compreender a multiplicidade e a pluralidade que envolve o conceito de infância bem como sua construção histórica, nos ajuda a entender como cada sociedade produz diferentes infâncias a 
partir de suas diversidades e desigualdades. De acordo com Felipe (2006); Bujes (2001) em nossa cultura ocidental a partir do século XVIII importantes transformações ocorreram em relação às representações de infância, família, bem como sua educação.

As crianças passaram a ser percebidas como sujeitos instituídos de uma "natureza" infantil, possuidoras de características específicas da idade. Vistas como inocentes, frágeis e heterônomas, ou seja, que necessitam da proteção dos adultos. A infância tem sido comumente associada à inocência, ingenuidade, pureza, sensibilidade, como um tempo de felicidade e brincadeiras, onde reina o que há de mais puro e bom.

Entretanto, para muitas crianças do mundo, este ideal de infância como "reino da brincadeira e felicidade" estão muito distantes. Sabemos que existem muitas crianças que não possuem o mínimo necessário para se viver com dignidade e que apesar dos avanços nas legislações e políticas no que diz respeito à garantia de direitos e proteção, para muitas crianças tais conquistas não se estendem. Muitas destas lutam diariamente contra maus tratos, abusos sexuais, abandono, até mesmo dentro de seus próprios lares e ainda aquelas crianças que vivem na rua, que precisam trabalhar para ajudar a família e que são postas à prostituição.

Uma dessas infâncias da contemporaneidade que muito se distancia do modelo de "infância ideal", são as que denomino como glitz (do inglês, brilho), categoria pouco explorada nos estudos sobre as infâncias e a sua ausência motivou-me a debruçar a seu respeito. As infâncias glitz são constituídas por aquelas crianças que desde a mais tenra idade têm a sua vida organizada e governada em torno dos concursos de beleza infantis.

Para Giroux (1998) “concursos de beleza infantis são lugares exemplares para examinar criticamente como o discurso da inocência mistifica a apropriação dos corpos infantis em uma sociedade que cada vez mais as sexualiza e comodifica" (GIROUX, 1998, p.36). Além da erotização dos seus corpos, nestes concursos as crianças aprendem bem cedo que é preciso competir para se dar bem na vida e que a beleza, dinheiro e fama são valores importantes e desejáveis.

Os concursos glitz (no Brasil são conhecidos como concursos de Miss Infantil) são organizados e realizados por rede de parceiros (agências de moda e de publicidade, estilistas, cabeleireiros, maquiadores, manicures, coreógrafos, fotógrafos, agenciadores e muitos outros). Uma rede que movimenta anualmente cerca de cinco bilhões de dólares. Estima-se que anualmente 250 mil crianças americanas participem de 5 mil concursos de beleza.

No Brasil os concursos de beleza infantis, apesar de serem de pequeno porte, se comparado aos americanos, há muitas crianças que participam destes. Em 2008, a gaúcha Natália Stangherlin conquistou o primeiro lugar no "Little Miss World” (Mini Miss Mundo), realizado no Equador. A premiação oferecida nesses concursos varia bastante: ganham-se troféus, coroas ou prêmios em 
dinheiro, brinquedo ou produto de beleza (em algumas competições é possível concorrer a carros, contrato com grandes agências, etc.).

Para atender as regras deste tipo de concurso e assim terem condições de ganhar as maiores premiações, as crianças (autorizadas pelos pais) e muitas vezes ao seu contragosto, necessitam passar por horas de tratamentos de beleza que envolve depilação nas pernas, bronzeamento artificial, unhas e cílios postiços, apliques nos cabelos, uso de grandes saltos e mais algumas horas em dentistas que fazem as famosas próteses de porcelana nos dentes (para que fiquem mais longos e menos infantis), além das aulas de dança, canto e postura. Muitas destas crianças participantes de concursos de beleza tentam dar sentido ao que fazem, vendo-o como uma brincadeira (embora boa parte das famílias deixe claro para as crianças que não se trata de brincar e sim de competir).

Os participantes de concursos de beleza infantis, são em sua maioria de classe média, famílias que gastam centenas de dólares com taxas de inscrição, passagem para o local do evento, cabeleireiro, bronzeamento, próteses dentárias, maquiagens, roupas e figurinos, além das aulas de dança e de performance. Todos estes gastos são entendidos pelas famílias como um investimento, pois concursos geram premiação e visibilidade para as crianças e ainda possibilidade de contratos (com emissoras de TV ou agências de publicidade). Segundo Giroux as famílias dos participantes acreditam que todo esse investimento pode ser compensatório:

[...] concursos de beleza infantis são legitimados como uma rota produtiva para colocarem seus filhos em carreiras lucrativas como modelos ou para ganharem bolsas para educação, prêmios financeiros e outros. A forma de racionalização mais usada para defender os concursos é que eles ajudam a construir a autoestima das crianças, a superar a timidez e ensinam como eles crescerem (1998, p. 4I).

De um modo geral, entre os membros da família, os pais das crianças não parecem ter uma participação significativa nos concursos, sendo conduzidos geralmente pelas mães. Estas possuem um papel central no que diz respeito a participação das crianças nos concursos, são elas que decidem quais concursos os filhos vão participar, que roupas vão usar, que coreografias vão fazer, dentre outros. No reality show "Pequenas Misses" da TLC têm sido recorrente a presença de mães, que se projetam nas filhas, acreditando que as meninas vão obter o que elas, mães, não conseguiram no passado, seja afirmação da beleza, fama, dinheiro, ou qualquer outra forma de compensação.

As Infâncias Glitz na tela da TV: descrição do artefato do midiático

O programa Pequenas Misses (Toddlers and Tiaras) é um reality show da TV americana que 
estreou na emissora TLC (antigo Discovery Travel \& Living) em 2009. No Brasil, o programa é veiculado pelo canal de TV por assinatura "Discovery Home and Health" (casa e saúde). Segundo o site da emissora, o canal é dedicado à beleza, bem estar e a vida em família. O canal foi pensado e planejado basicamente para mulheres.

O programa escolhido para este estudo, o "Pequenas Misses", tem sido produzido pela "Authentic Enterainment, Inc.” empresa especialista em Reality Shows para TV a cabo. Ao contrário do Brasil, em que os programas são produzidos pelas próprias emissoras, exceto programas estrangeiros, nos EUA as emissoras compram os programas de diferentes produtoras.

O programa "Pequenas Misses" acompanha a saga das famílias em busca de coroas cintilantes, títulos pomposos e dinheiro. Os preparativos se intensificam durante a semana anterior ao último desfile. Desde o agendamento em manicures e cabeleireiros aos toques finais nas roupas, além de vários ensaios e sessões de orientação, cada criança se prepara para seu desempenho final. No palco, a decisão cabe aos juízes, mas ainda assim, os pais tentam fazer de tudo para provar que seus filhos são os mais bonitos se colocando na maioria das vezes contra à vontade das crianças.

Para cada episódio são escolhidas três ou quatro competidoras que protagonizarão o programa, que possui temáticas bem diversificadas: relacionamentos conflituosos entre pais e filhos, transformação e adequação dos corpos infantis para atender às exigências da competição, dá-se ênfase nas performances das crianças e na premiação. Sobre o público-alvo, no Brasil o programa se endereça a um "modelo" específico de mulher, casada, com filhos e de classe média ou alta. O programa também atrai garotas adolescentes e segundo argumentos em debates nos fóruns sobre o programa na internet, a forma pela qual as crianças são expostas, também atrai pedófilos.

Atualmente o programa está em sua $6^{a}$ temporada nos EUA e na $4^{a}$ temporada no Brasil e tem sido constantemente alvo de diversas críticas e até de ações na justiça, por exibirem crianças sendo abusadas psicologicamente ou fisicamente para atender às exigências estéticas dos concursos, como o caso de uma mãe que perdeu a guarda da filha de 8 anos, por confessar em um episódio da $1^{\text {a }}$ temporada que aplicava Botox na criança e outro caso de uma mãe que colocava preenchimento para os seios no vestido de uma criança de 5 anos.

\section{Abordagem Metodológica}

Como escolha metodológica para análise deste artefato midiático, elegeu-se a análise do discurso (AD) a partir das incursões de Michel Foucault. Embora este filósofo francês nunca tenha se intitulado um analista do discurso, no conjunto de suas obras, fruto de pesquisas de grande relevância em sua época e nos tempos atuais, Michel Foucault apresenta a noção de discurso, a partir da sua 
relação com a legitimação de saberes e o meio pelo qual se pode chegar à constituição dos sujeitos.

Outros conceitos como os de formação discursiva, função-enunciativa, posiçãosujeito/função autor, biopoder, ordem do discurso, acontecimento, arquivo e heterogeneidade discursiva vêm sendo ao longo dos anos incorporadas à análise do discurso, e inspiram, hoje, inúmeros trabalhos nos mais diferentes campos de conhecimento.

Fischer (2002) argumenta que analisar um discurso mesmo que o documento considerado seja a reprodução de um simples ato de fala individual, não nos faz estar diante da manifestação de um sujeito, mas nos possibilita defrontar com um lugar de sua dispersão e de sua descontinuidade, já que o sujeito da linguagem não é um sujeito em si, idealizado, essencial, origem inarredável do sentido: ele é ao mesmo tempo falante e falado, porque através dele outros ditos se dizem.

Para a análise dos enunciados, selecionou-se trechos de três episódios do reality show de TV Pequenas Misses: $12^{\circ}$ "Fancy Faces" e $13^{\circ}$ "Viva Las Vegas" (3 temporada), $3^{\circ}$ "Circles City Stars" ( $4^{a}$ temporada) exibidos no Brasil durante os meses de julho e agosto de 2013. O programa Pequenas Misses atualmente é exibido semanalmente, nas sextas-feiras das $21 \mathrm{~h}$ às $22 \mathrm{~h}$ e reprisado aos domingos das $13 \mathrm{~h}$ às $14 \mathrm{~h}$ e não segue uma sequência linear, podendo em uma semana apresentar um episódio da quarta temporada e na outra um episódio da terceira ou quinta temporada.

"Pra vencer é preciso jogar as regras do jogo": as imposições dos concursos de beleza para a transformação dos corpos infantis

De todas as temáticas que circundam o programa, uma delas em específico despertou o meu interesse. Acompanhando atentamente as rotinas das participantes dos concursos de beleza infantis, percebi que em cada episódio, determinados discursos se colocavam como verdades incontestáveis: a de que os corpos infantis precisam ser radicalmente transformados. Portanto, se dará aqui a ênfase para as imposições e exigências estéticas dos concursos de beleza para os corpos infantis.

No episódio $13^{\circ}$ da terceira temporada, acompanhamos a rotina de preparação de Ellisyn de 5 anos de idade, que já participa de concursos de beleza desde os seus dois anos e já coleciona inúmeros títulos e premiações. A infância da participante Ellisyn tem sido produzida a partir de discursos que tentam convencê-la que valores como beleza, fama e dinheiro são "meios essenciais" para a felicidade e sucesso. 
Trecho 1: Depoimento da mãe da participante Ellisyn de 5 anos.

"Para convencer a minha filha a participar de concursos, digo muitas vezes para ela que beleza ajuda muito na vida. Se você é bonita, é tratada de forma de diferente. Quando eu era mais jovem eu fui modelo, mas tive filhos e engordei. Um dia você tem tudo e depois você não tem nada. Para os concursos você tem que dar o máximo de sie entrar nas regras do jogo".

Fonte: TLC (2013).

Analisando as cenas que seguem após o depoimento da mãe, "as regras do jogo" vão se revelando aos nossos olhos. Para uma criança concorrer à premiação máxima (o Grand Supreme) esta precisa se submeter a uma série de transformações estéticas em seu corpo em desenvolvimento. Para ter chances de vencer o concurso, a participante Allysn precisou usar dentes postiços, por estar na fase do seu desenvolvimento em que os dois dentes incisivos (de leite) frontais caíram, para nascerem no lugar os dentes definitivos.

O processo de formação dos dentes das crianças é ignorado pela organização do concurso, que exige em termos claros, um "sorriso perfeito", como condição para conquistar os juízes. Além da imposição dos dentes postiços, a cor da pele da participante também precisou ser também modificada, afinal, segundo os discursos dos estilistas, maquiadores e esteticistas internacionais, o bronzeamento artificial propõe que se tenha a pele "da cor de verão" o ano inteiro.

As participantes desses concursos também são obrigatoriamente submetidas uma técnica chamada bronzeamento a jato, que consiste na aplicação de um produto químico que reage na pele, surgindo assim o desejado "tom bronzeado". Essas e outras inovações estéticas tornam-se "naturalizadas" por trás do discurso da possibilidade de transformar o corpo através dos avanços tecnológicos (JÚNIOR, et al., 2008 apud CHAVES, 2003).

Todas essas imposições aos corpos infantis não surgiram por um mero acaso, pois o corpo, tanto das crianças com os dos adultos ao longo da história, sempre foi sujeito à transformações. Mudaram-se as formas ideais, seu peso, seu funcionamento e seus ritmos. As representações de beleza, saúde, doença, juventude, virilidade e outros, se convertem, incorporam outros contornos e se produzem ao longo da história, novos corpos (JÚNIOR, et al., 2008). Com as tecnologias, as mudanças corporais se dão em uma velocidade ainda maior e cada nova técnica torna-se altamente desejada e valorizada.

Atualmente, inúmeros produtos e tecnologias para essas transformações, interpelam nossos desejos e carências e são alimentados pelo que (JÚNIOR, et al., 2008) definem como: "processos de 
retificação, realinhamento e reconformação da indústria de aparência", em que os corpos se apresentam na condição de passarela na qual a moda desfila. Sustenta-se assim, por meio dessas pedagogias, que se deve buscar, desde muito cedo, ser bela (o), mesmo que para isso seja necessário os mais torturantes sacrifícios.

Tais discursos, que se sustenta ao longo do programa a partir das diversas falas e das imagens que nos interpelam, produzem efeitos de verdade sobre o que é ser bonita em nossa sociedade (DORNELLES 2010, p. 183). A valorização dada aos corpos transformados pela sociedade do consumo nos seduz e nos faz acreditar que o corpo é o primeiro local da identidade e que este precisa estar em visibilidade. Isso fica muito claro quando ouvimos os ditos populares "a primeira impressão é a que fica" e "imagem é tudo".

Para Goellner (2003) o culto ao corpo como hoje vivenciamos, tem seu início ao final do século XVIII e vai se intensificando a partir daí. Mais precisamente no século XIX, o corpo adquire relevância nas relações que se estabelecem entre os indivíduos. Surge então, uma moral das aparências que diferencia o que se aparenta ser, com o que de fato, se é. Analisando o artefato cultural "Pequenas Misses" e em especial a fala da mãe da participante Allsyn, a concepção beleza no discurso enunciado está associada diretamente as transformações do corpo, que vão determinar aquilo que seremos na vida (vencedores ou fracassados) determinando ou não, a nossa felicidade.

Em seguida, destaco um trecho extraído de uma cena do episódio $12^{\circ}$ da terceira temporada de título "Fancy Faces" que acompanha a rotina da participante SamiJo (uma criança de 1 ano e 8 meses) que desde os 6 meses de vida, já participa de concursos de beleza glitz:

Trecho 2: Depoimentos da Tricia, mãe da participante Samijo de 15 meses (1 ano e 8 meses) e em seguida trecho de um diálogo entre Tricia e a treinadora da sua filha:

"'Decidi colocar SamiJo em concursos, pois era por isso que en queria ter uma filha. [...] SamiJo far. bronzeamento, vai para o cabeleireiro e faz maquiagem para o concurso. [...] Na categoria da Sammy não costumam se bronzear, geralmente ela é a unica. Queremos competir com crianças mais velhas."

Tricia (mãe daparticipante): - Iremos com glitz, totalpara esse concurso. Estamos pensando em unhas postiças.

(Surge a imagem do bebê SamiJo com unhas postiças)

Treinadora: - Ficou esquisito!

Tricia (mãe daparticipante): - Por que ficou esquisito?

Treinadora: - Porque SamiJo tem 1 ano e 8 meses e está com unhaspostiças enormes. 
O depoimento da mãe e em seguida o diálogo com a treinadora da participante, chocam grande maioria das pessoas que veem o programa. Afinal, trata-se de uma criança de um ano e oito meses, sendo submetida a processos que nem mesmo sabe do que se trata e nem pode escolher se o quer. A bebê Samijo que ainda tenta se equilibrar com as duas pernas e aprende as primeiras palavras, já carrega sobre si a responsabilidade de ser uma vencedora de concursos de beleza.

Samijo segundo depoimento da sua mãe, veio ao mundo com uma única missão: realizar o sonho que a mãe tinha de ser Miss América. Dentre os tantos sentimentos que nos surgem e que nos fazem questionar o que está em jogo nessas falas, por que essas cenas tanto nos chocam? Que concepções construímos de infância que nos leva a perplexidade diante do que é visto nas falas? Será que infância de Samijo poderia ser diferente? Quem dá aos pais o direito de decidir o que os filhos serão desde a sua concepção?

Para tratar dessas questões, é necessário discorrer brevemente sobre como surgiu à ideia de infância ou de como a infância "entrou em cena". Segundo o historiador francês Phillippe Ariès, no livro "A História Social da Criança e da Família" (1981) a infância que aparentemente é algo que sempre existiu, é para o autor uma invenção recente. Segundo Ariès, no período chamado de Idade Média, as crianças não recebiam tratamento diferenciado dos adultos, elas viviam soltas e desde cedo aprendiam determinadas técnicas e tal como seus pais, trabalhavam.

A noção de uma infância protegida e separada do mundo dos adultos, não existia. Nos últimos cinco séculos, houve uma considerável mudança no que seria a ideia de infância. A criança passou a ser estudada, cuidada, surgiram os especialistas na infância. Segundo DORNELES (2005, p.21) a invenção da infância está associada a uma série de práticas, no que diz respeito à vida e ao cuidado das crianças, tornando-as cada vez mais dependentes dos adultos, pois a criança sendo frágil, maleável, carecendo de razão e inocente por "natureza" semelhante a uma cera que pode ser moldada e retocada, necessita então de direção e cuidado.

E de quem seria a responsabilidade desses cuidados e direcionamento? A invenção da infância produziu mudanças no ambiente social doméstico. A família se solidifica e precisa arcar com os cuidados, a higiene e a limpeza do espaço doméstico, bem como a sustentação moral dos seus membros (DORNELES, 2005, p. 41). É a família que toma as decisões sobre a vida das crianças, sendo elas boas ou más. Passa a ser obrigação da família suprir as necessidades primárias (alimentação, higiene e vestuário), secundárias (escolarização e lazer) e terciárias (afeto e proteção).

No depoimento da mãe da participante Samijo se reforça essa premissa moderna de família, que deve controlar e decidir os rumos da vida de uma criança. Sob o argumento de ter o poder para governar e decidir, já que a criança é heterônoma, a pequena Samijo é submetida a toda uma série de abusos e imposições ao seu corpo recém formado, sem poder se defender, sem ter como buscar 
socorro, pois tais imposições são vistas como "naturais", boas e desejáveis.

Diferente de Samijo que ainda não pode dizer claramente o que pensa (mesmo se expressando com gritos e lágrimas que são justificadas pela família “como birra de bebê”) uma forma encontrada pela criança de resistir ao governo dos corpos (FOUCAULT, 1984a; 1984b), outras crianças na mesma situação tentam contestar e escapar das imposições a que são submetidas. Vejamos o trecho a seguir extraído do $3^{\circ}$ episódio da quarta temporada intitulado: "Circle City Stars and Cars".

Trecho 3: Diálogo entre Lori (mãe) e Alaska de 8 anos, participante de concursos:

'Lori (mãe daparticipante):- Se tingir os cílios, não saífilha!

Alaska (participante): - Eu não quero! Eu não quero que meus olhos fiquem assim.

Mãe (depoimento em outro cenário):

- Eu estava esperando que eu realmente conseguisse fazer com que a Alaska deixasse pintar os cílios, porque os dela são muito claros. [...] E desse jeito não temos que nos preocupar com a maquiagem borrando.

(Retorna a cena do diálogo entre mãe e filha)

Mãe: - Ok! Pintar ou não a decisão é sua!

Alaska: -Está bom! Então eu digo que não queropintar!

Alaska (depoimento em outro cenário, distante dospais):

-Eu não queropintar os meus cilios, estou com medo que machuquem os meus olhos.

(No meio da cena, o pai da menina entra no diálogo entre mãe e fillha e dir que ela pintará os cílios para encerrar aquela discussão).

Alaska (depoimento em outro cenário, distante dospais):

- Eu deixei pintarem meus cílios, mas sópor que todo mundo queria muito mesmo. Agora que estão tingidosjá não estou gostando. Esses não parecem os meus cílios, bom, eles realmente não são meus!

Fonte: TLC (2013).

Considero o trecho deste último quadro, o mais impactante dentre os episódios analisados, pelos jogos discursivos e a violência que as falas (juntamente com a cena) nos interpelam. Em uma primeira análise, retomam-se as críticas sobre a violência e os abusos que se impõem sobre o corpo infantil e emergem os questionamentos sobre onde estariam às instâncias jurídicas e de proteção para amparar essa criança vítima de tantos abusos?

Segundo a Declaração dos Direitos da Criança (1959) no seu artigo $2^{\circ}$ : “Todas as crianças devem ser protegidas pela família, pela sociedade e pelo Estado, para que possam se desenvolver fisicamente e intelectualmente", direito esse, que tem sido negado, quando presenciamos uma brutal imposição de processos de modificações corporais, os quais são socialmente naturalizados pela 
repetitiva divulgação nos espaços/artefatos culturais. Discursos de verdade, que nos interpelam a perceber o corpo não por si mesmo, mas a partir de uma noção de corpo ideal.

Analisando as falas/cenas em destaque, nota-se a existência do que Fischer (2008) chama de interposição de olhares. Em que de um lado vemos os familiares reforçarem discursos de espetáculo como o "vale tudo para ficar bonita" e do outro surge aos nossos olhos, uma criança que se coloca abertamente contra toda a legitimação das transformações corporais, postas como necessárias e obrigatórias à participante.

A participante Alaska é uma criança que vive uma infância glitz, em que os discursos de poder: da autoridade dos pais, da rede de especialistas impõem para ela uma mudança radical em seu corpo, para vencer uma competição de beleza. Em depoimento isolado do grupo familiar, a participante Alaska, confessa em frente às câmeras, único lugar que parece ter interesse em ouvi-la, ter cedido à pressão dos seus pais, assumindo em seu corpo uma identidade que não lhe pertence, uma identidade fake. A participante consegue perceber como as identidades se constituem a partir do seu corpo, de como essas transformações nos distanciam de nós mesmos, reagindo com total estranhamento à imposição a qual é submetida, ao contrário de toda uma rede de experts da estética, organizadores e familiares se negam a ver esses processos.

Para Mendes (2006) em seu artigo "O corpo em Foucault: superfície de disciplinamento e governo" a cena de autoconfissão da participante Alaska, direcionada para as câmeras, caracteriza-se como técnica de tornar-se objeto de conhecimento de si próprio (conhecer-se para governar-se) sendo esta decisiva para “optarmos" por formas mais "conscientes", ou pelo menos mais prazerosas de sermos subjetivados, ou mesmo de contribuir para outros processos de subjetivação do eu.

A análise dos jogos discursivos presentes na cena da participante Alaska, remeteu-me a análise do Filme "Pequena Miss Sunshine" (2007) em que a pesquisadora Rosa Maria Bueno Fischer (2008) se propondo a ir além das críticas já tão comuns aos concursos de beleza, mostra como as narrativas que se entrelaçam para dizer algo, acabam por nos dizer um pouco mais. Enxergar mais sobre essas infâncias que "não podem ser integradas, nem identificadas, nem compreendidas, nem previstas", ou que podem ser nomeadas como “interrupção, novidade, catástrofe, surpresa, começo, nascimento, milagre, revolução, criação, liberdade" (LAROSSA, 2001, p. 282).

A participante Alaska é um exemplo das infâncias que tentam escapar, que fogem do controle dos pais, do controle dos corpos, de determinados modos de constituição de identidades. Apenas cede às pressões dos familiares, por se ver, naquela situação sem alternativas. Escapa, por compreender que o seu o corpo e sua identidade não podem ser impostos, escapa por resistir a discursos tão convincentes dos modos de subjetivação, escapa por reagir com estranheza ao naturalizado e por se recusar a "ser apenas a passarela pela qual a padronização deve passar". 


\section{Considerações finais}

A partir da análise de trechos extraídos do programa Pequenas Misses evidencia-se a produção de novas concepções de infâncias na contemporaneidade. Uma dessas é a infância glitz, produzida por uma rede de experts que vêm submetendo muitas crianças a uma série de abusos psicológicos e físicos, a partir de imposições estéticas aos seus corpos recém-formados. Crianças que não podem se defender, nem buscar socorro, pois os discursos que sustentam tais práticas abusivas são enunciadas pelos dispositivos de poder/saber como "naturais” e necessárias.

Apesar dos tantos avanços no campo das políticas, da legislação e com o surgimento de inúmeras instituições de proteção e amparo as crianças, bem como os esforços governamentais em todo mundo para garantir e protegê-las de abusos e explorações, estas são em diferentes realidades geográficas, culturais e socioeconômicas vítimas de abusos diariamente. No contexto brasileiro, dos tipos de abusos e exploração aceitos em nossa sociedade como tais, os dados da Organização Internacional do Trabalho (OIT) destacam que por ano, são registrados cerca de 100 mil casos de abuso e exploração de crianças e adolescentes. E destes casos, menos de 20\% chegam ao conhecimento das pessoas encarregadas de tomar às devidas providências. Quanto aos abusos tratados neste estudo, que dizem respeito a uma brutal imposição de modificações corporais nas crianças e que têm sido naturalizados e banalizados pela repetitiva divulgação nos espaços/artefatos culturais, tal quadro éainda mais agravante. $\mathrm{Na}$ ausência de amparo e proteção legal, algumas crianças tentam escapar, resistir, fugir do controle dos corpos e de determinados modos de constituição e governo de suas identidades. São estas infâncias, que como dito por Jorge Larrosa, temos que pensá-las na medida em que escapam, na medida em que estas inquietam tudo o que sabemos e produzimos ao seu respeito, na medida em que estas suspendem o que podemos e na medida em que colocam em xeque os lugares que construímos para elas e a presunção da nossa vontade de abraçá-las. 
Referências

ARIÈS, Philippe. Historia social da família e da infância. Rio de Janeiro: Zahar, 1981.

BUJES, Maria Isabel. Infância e maquinarias. Tese de doutorado. Faculdade de Educação, Universidade Federal do Rio Grande do Sul. 2001.

CORAZZA, Sandra. Infância \& Educação. Era uma vez... Quer que conte outra vez? Petrópolis: Vozes, 2002.

DORNELLES, Leni Vieira. Infâncias que nos escapam: da criança na rua à criança cyber. Petrópolis: Vozes, 2005.

FELIPE, Jane. Afinal, quem é mesmo pedófilo? Cadernos Pagu, v. 26, 2006.

FISCHER, Rosa Maria Bueno. Pequena Miss Sunshine: para além de uma subjetividade exterior. Pro-Posições (UNICAMP), v. 19, p. 47-57, 2008. Disponível em:

http://www.ufrgs.br/nemes/download.html. Acesso em: 27 de maio de 2013.

FOUCAULT, Michel. Vigiar e Punir. 3a ed. Petrópolis: Vozes, 1984 a.

FOUCAULT, Michel. História da Sexualidade Vol. I: A vontade de saber. 5a. Edição Rio de Janeiro: Graal, 1984b.

GIROUX, Henry A. Nymphet fantasies: child beauty pageants and the politics of innocence. Social Text, v. 16, n.4, p. 31-53, 1998.

GOELLNER, Silvana Vilodre. A produção Cultural do Corpo. In: LOURO, Guacira Lopes; NECKEL, Jane Felipe, GOELLNER, Silvana Vilodre (Orgs.). Corpo, gênero e sexualidade: Um debate contemporâneo na educação. Petrópolis, RJ, 2003, cap. 2.

JÚNIOR, José Aelson S.; LADISLAU, Carlos Rogério; NIQUINI, Cláudia Mara. A moda na carne viva: Imagem, Corpo e Consumo: aproximações teóricas. In: Congresso Brasileiro de Ciências do Esporte, 15; 2007. Olinda - PE. Disponível em: http://www.cbce.org.br/cd/lista_area_03.htm Acesso em 15 de maio de 2013.

LARROSA, Jorge. Dar a palavra. Notas para uma lógica da transmissão. In: LARROSA, Jorge; 
SKLIAR, Carlos. Habitantes de Babel: políticas e poéticas da diferença. Belo Horizonte: Autêntica, 2001. P. 281-295.

Pedagogia Profana: danças, piruetas e mascaradas. $4^{a}$ ed. Belo Horizonte: Autêntica, 2001b. 208p.

TLC. Toddless and Tiaras. Discovery Home and Health. 2013. 